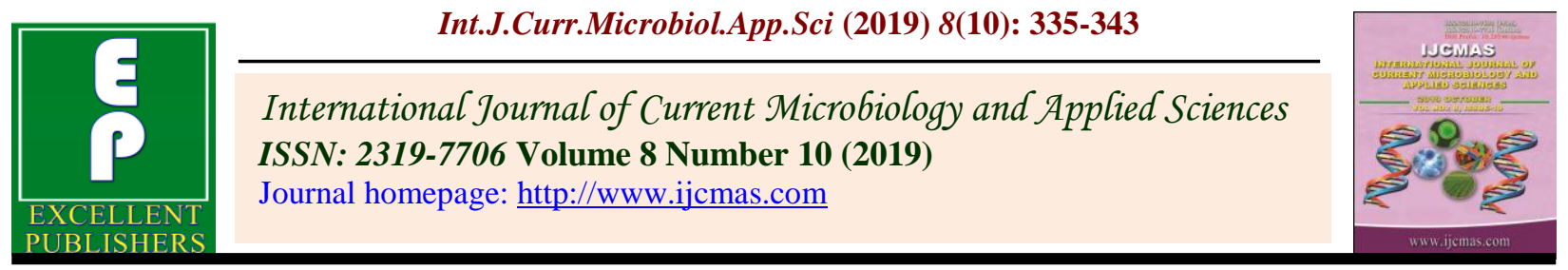

Original Research Article

https://doi.org/10.20546/ijcmas.2019.810.034

\title{
Effect of the different Rooting Media and IBA Concentrations on Yield of Carnation (Dianthus caryophyllus) Cuttings cv. Gaudina
}

\author{
Sushil Kumar*, Arvind Malik and Ritu Yadav \\ Department of Horticulture, CCS Haryana Agricultural University, Hisar, Haryana, India \\ *Corresponding author
}

\section{A B S T R A C T}

Keywords

Auxins, Media,

Flower, Plant growth regulators, Ornamental

Article Info

Accepted:

xx September 2019

Available Online:

xx October 2019
The experiment was conducted to study the efficacy of different rooting media and IBA concentrations on yield of carnation cuttings cv. Gaudina during 2017-2018 and the experiment was conducted in Randomized Block Design (RBD). Different rooting media and IBA concentrations studied recorded superior rooting parameters over control. Among the different rooting media studied, cocopeat + river sand (1:1) and among the IBA concentration, $200 \mathrm{ppm}$ IBA was found the best. Within the interaction treatments, the best combination was found with the cocopeat + river sand (1:1) rooting media with $200 \mathrm{ppm}$ IBA concentration for different flowering parameters like days to initiation of first flower bud (20.47 days), days to 50 percent flowering, number of floral buds per plant (6.20), number of flowers per plant $(5.80)$, diameter of flower $(5.61 \mathrm{~cm})$ and stalk length of flower $(58.12 \mathrm{~cm})$.

\section{Introduction}

Floriculture is a conventional farming activity in India related with cultivation of different types of flowers and ornamental plants, having immense potential for providing gainful selfemployment among small and marginal farmers. The demand for ornamental flowers is ever increasing in international and domestic market with the improvement in standard of living and quality of life. Floriculture has blossomed into commercial activity with a considerable growth and a useful crop diversification option, particularly for small farmers over the past three decades.

Carnation (Dianthus caryophyllus L.) belongs to the family Caryophyllaceae. It is grown in several parts of the world and is believed to be the native of Mediterranean region (Benny et al., 2017). Carnation is a valuable flower crop having great commercial value mainly as a cut flower because of its excellent keeping quality, wide range of colors and forms. 
Carnation, apart from producing cut flowers can also be used in gardening for bedding, edging, borders and pots purposes (Dole and Wilkins, 2005). It ranks next only to rose and chrysanthemum in global floriculture trade (Sanyat et al., 2006). These are vegetatively propagated by mainly terminal cuttings.

Rooting media is the important factor which plays a major role in quality flower production and rooting of cuttings of carnations. River sand, vermiculite, perlite, cocopeat, sphagnum moss, etc. and their different combinations are being used as rooting media for carnation cuttings. Carnations are highly responsive to micronutrients, fertilizers and growth regulators. Exogenous application of plant growth regulators enhances the growth (ElNaggar et al., 2009) and flowering of ornamentals and hence yields. Plant growth regulators play a vital role for enhancing quality and yield of many commercial flowers. IBA and NAA are most commonly used auxins (Kaviarasu and Selvaraj, 2016).Hence, the study was conducted to find out the best interaction of rooting media and optimum dose of IBA for better flowering and yield parameters in carnation.

\section{Materials and Methods}

The study was conducted during 2017-18 at Centre for Quality Planting Material, CCSHAU, Hisar, Haryana. In this experiment, terminal cuttings with $10-15 \mathrm{~cm}$ length and 2-4 pairs of leaves of standard type of carnation cv. Gaudina were used. Different rooting media used were river sand, cocopeat, vermicompost + cocopeat + river sand $(1: 1: 1)$, vermicompost + cocopeat (1:1), vermicompost + river sand $(1: 1)$, cocopeat + river sand $(1: 1)$ and cocopeat + vermiculite + perlite $(3: 1: 1)$. The growth hormone used was Indole Butyric Acid (IBA) with three different concentrations 0 (control), 100 and 200 ppm. Terminal ends of cuttings were dipped in IBA solution for 5 minutes. The treated cuttings were planted in protrays kept in semi-climate controlled greenhouse nursery under optimum conditions. After the successful establishment of cuttings, the rooted cuttings were transplanted in beds with due care and planted in Randomized Block Design (RBD). Biometric observations like days to initiation of first flower bud, days to 50 percent flowering, number of floral buds per plant, number of flowers per plant, diameter of flower and stalk length of flower were recorded at appropriate time. For recording the observations, five representative plants were selected randomly in each replication and average was worked out and the data were statistically analyzed using sas version 9.4 (Panse and Sukhatme, 1985).

\section{Results and Discussion}

\section{Days to initiation of first flower bud}

The different rooting media and IBA concentration significantly decreased the number of days to initiation of first flower bud.

The minimum days to initiation of first flower bud (21.80 days) in carnation was recorded with cocopeat + river sand (1:1). The maximum days to initiation of first flower bud was recorded with river sand alone (30.29 days) followed by 28.98 days with vermicompost + cocopeat + river sand $(1: 1: 1)$. Application of 200 ppm IBA recorded the least number of days to initiation of first flower bud (24.91 days), while the 0 ppm IBA recorded the highest number of days to initiation of first flower bud (29.55 days). Among the interaction, cocopeat + river sand (1:1) rooting media with 200 ppm IBA recorded the lowest number of days to initiation of first flower bud (20.47 days) followed by the vermicompost + river sand (1:1) with 200 ppm IBA (22 days). This might be due to the early plant 
establishment in field and better root system resulted in better uptake of nutrients and water (Table 1).

These findings about the differences in no. of days to bud initiation as influenced by different concentrations of growth regulators applied were in conformity with the findings of Kumar et al., (2012) in Carnation, Baghele et al., (2012) in Rose, Rani and Singh (2013) in Tuberose and Maitra and Roychowdhury (2015) in Carnation.

\section{Days to 50 percent flowering}

The different rooting media and IBA concentration significantly decreased the number of days to 50 percent flowering. The minimum days to 50 percent flowering (39.67 days) in field was observed with cuttings which were grown in cocopeat + river sand $(1: 1)$ rooting media in nursery. This might be due to the better root system and plant establishment in the field. IBA concentration had significant effect on the days to 50 percent flowering. Cuttings treated with 200 ppm IBA recorded the least number of days to 50 percent flowering (43.50 days). The combinations of rooting media and IBA concentration were found non-significant. This result resembles the findings of Jawaharlal et al., (2001), who reported that plants grown in cocopeat medium took minimum days for appearance of first floral bud in Anthurium plants and hence ultimately took minimum days to $50 \%$ flowering.

Talukdar et al., (1991) also observed the same results in orchid wherein they found that coconut husk + moss produced earliest bud emergence and hence flower opening (Table 2).

\section{Number of floral buds per plant}

The different rooting media and IBA concentration significantly increased the number of floral buds per plant. Among the rooting media, the maximum number of flower buds per plant (5.62) was recorded with the cuttings planted in cocopeat + river sand (1:1) rooting media. Treatment of cuttings with $200 \mathrm{ppm}$ IBA recorded the maximum number of flower buds per plant (5.25). The best combination for number of floral buds per plant was found with cocopeat + river sand (1:1) rooting media with 200 ppm IBA (6.20). Increased concentration of IBA resulted in better rooting, more number of roots and more number of leaves which resulted in maximum production of phytosynthates and ultimately increases the number of flower buds. The better results may be due to good vegetative growth converted to reproductive growth of plants. These results were in accordance with the studies of Anujeet al., (2004) who reported maximum number of flowers buds per plant for Gerbera in cocopeat + FYM (1:1) medium. This finding also gets support from the work of Jawaharlal et al., (2001) in Anthurium andSekar and Sujata (2001) in Gerbera.

\section{Number of flowers per plant}

Table 12 indicates that different rooting media and IBA concentration significantly increased the number of flowers per plant.

The maximum number of flowers per plant (5.42) was recorded with the cocopeat + river sand (1:1). Treatment of cuttings with 200 ppm IBA recorded the maximum number of flowers per plant (4.91), while it was found minimum in case of 0 ppm IBA (3.94).

The best combination for number of flowers per plant was found with cocopeat + river sand (1:1) rooting media with 200 ppm IBA (5.80), while it was found minimum with control (3.27). Baheer (1997) and Barreto and Jagtap (2002) reported that cocopeat combined with compost (1:1) produced maximum number of flowers in gerbera. 
Table.1 Effect of different rooting media and IBA concentrations on days to initiation of first flower bud in carnation cv. Gaudina

\begin{tabular}{|c|c|c|c|c|}
\hline \multirow{2}{*}{ Rooting media } & \multicolumn{2}{|c|}{ Concentration of IBA (ppm) } & \multirow{2}{*}{ Mean } \\
\cline { 2 - 4 } & $\mathbf{0}$ & $\mathbf{1 0 0}$ & $\mathbf{2 0 0}$ & \\
\hline River sand (Control) & 35.33 & 28.20 & 27.33 & $\mathbf{3 0 . 2 9}$ \\
\hline Cocopeat & 32.00 & 28.67 & 25.40 & $\mathbf{2 8 . 6 9}$ \\
\hline Vermicompost + Cocopeat + River sand (1:1:1) & 30.00 & 28.53 & 28.40 & $\mathbf{2 8 . 9 8}$ \\
\hline Vermicompost + Cocopeat (1:1) & 30.00 & 29.73 & 25.20 & $\mathbf{2 8 . 3 1}$ \\
\hline Vermicompost + River sand (1:1) & 26.87 & 26.87 & 22.00 & $\mathbf{2 5 . 2 4}$ \\
\hline Cocopeat + River sand (1:1) & 22.67 & 22.27 & 20.47 & $\mathbf{2 1 . 8 0}$ \\
\hline Cocopeat + Vermiculite + Perlite (3:1:1) & 30.00 & 26.53 & 25.53 & $\mathbf{2 7 . 3 6}$ \\
\hline Mean & $\mathbf{2 9 . 5 5}$ & $\mathbf{2 7 . 2 6}$ & $\mathbf{2 4 . 9 1}$ & \\
\hline C.D. at 5\% & Media & Concentration & Media X \\
& & of IBA & Concentration \\
of IBA
\end{tabular}

Table.2 Effect of different rooting media and IBA concentrations on days to 50 percent flowering in carnation cv. Gaudina

\begin{tabular}{|c|c|c|c|c|}
\hline Rooting media & \multicolumn{2}{|c|}{ Concentration of IBA (ppm) } & \multirow{2}{*}{ Mean } \\
\cline { 2 - 4 } & $\mathbf{0}$ & $\mathbf{1 0 0}$ & $\mathbf{2 0 0}$ & \\
\hline River sand (Control) & 53.33 & 50.00 & 48.80 & $\mathbf{5 0 . 7 1}$ \\
\hline Cocopeat & 50.13 & 45.00 & 44.47 & $\mathbf{4 6 . 5 3}$ \\
\hline Vermicompost + Cocopeat + River sand (1:1:1) & 48.20 & 43.67 & 43.47 & $\mathbf{4 5 . 1 1}$ \\
\hline Vermicompost + Cocopeat (1:1) & 48.00 & 46.07 & 44.67 & $\mathbf{4 6 . 2 4}$ \\
\hline Vermicompost + River sand (1:1) & 49.67 & 45.47 & 44.40 & $\mathbf{4 6 . 5 1}$ \\
\hline Cocopeat + River sand (1:1) & 41.33 & 40.67 & 37.00 & $\mathbf{3 9 . 6 7}$ \\
\hline Cocopeat + Vermiculite + Perlite (3:1:1) & 50.20 & 43.27 & 41.67 & $\mathbf{4 5 . 0 4}$ \\
\hline Mean & $\mathbf{4 8 . 7 0}$ & $\mathbf{4 4 . 8 8}$ & $\mathbf{4 3 . 5 0}$ & \\
\hline C.D. at 5\% & Media & $\begin{array}{c}\text { Concentration } \\
\text { of IBA }\end{array}$ & $\begin{array}{c}\text { Media X } \\
\text { Concentration } \\
\text { of IBA }\end{array}$ \\
\hline & & & \multicolumn{2}{c|}{ NS } \\
\hline
\end{tabular}


Table.3 Effect of different rooting media and IBA concentrations on number of floral buds per plant at bud stage in carnation cv. Gaudina

\begin{tabular}{|c|c|c|c|c|}
\hline Rooting media & \multicolumn{3}{|c|}{ Concentration of IBA (ppm) } & \multirow{2}{*}{ Mean } \\
\cline { 2 - 4 } & $\mathbf{0}$ & $\mathbf{1 0 0}$ & $\mathbf{2 0 0}$ & \\
\hline River sand (Control) & 3.40 & 3.80 & 4.40 & $\mathbf{3 . 8 7}$ \\
\hline Cocopeat & 4.20 & 4.53 & 5.00 & $\mathbf{4 . 5 8}$ \\
\hline Vermicompost + Cocopeat + River sand (1:1:1) & 4.20 & 5.00 & 5.60 & $\mathbf{4 . 9 3}$ \\
\hline Vermicompost + Cocopeat (1:1) & 4.00 & 4.40 & 5.60 & $\mathbf{4 . 6 7}$ \\
\hline Vermicompost + River sand (1:1) & 4.80 & 5.00 & 5.13 & $\mathbf{4 . 9 8}$ \\
\hline Cocopeat + River sand (1:1) & 5.07 & 5.60 & 6.20 & $\mathbf{5 . 6 2}$ \\
\hline Cocopeat + Vermiculite + Perlite (3:1:1) & 4.07 & 4.33 & 4.80 & $\mathbf{4 . 4 0}$ \\
\hline Mean & $\mathbf{4 . 2 5}$ & $\mathbf{4 . 6 7}$ & $\mathbf{5 . 2 5}$ & \\
\hline C.D. at 5\% & Media & Concentration & Media X \\
& & of IBA & Concentration \\
& & & of IBA \\
\hline
\end{tabular}

Table.4 Effect of different rooting media and IBA concentrations on number of flowers per plant at full bloom stage in carnation cv. Gaudina

\begin{tabular}{|c|c|c|c|c|}
\hline Rooting media & \multicolumn{3}{|c|}{ Concentration of IBA (ppm) } & \multirow{2}{*}{ Mean } \\
\cline { 2 - 4 } & $\mathbf{0}$ & $\mathbf{1 0 0}$ & $\mathbf{2 0 0}$ & \\
\hline River sand (Control) & 3.27 & 3.80 & 4.00 & $\mathbf{3 . 6 9}$ \\
\hline Cocopeat & 3.80 & 4.00 & 4.40 & $\mathbf{4 . 0 7}$ \\
\hline Vermicompost + Cocopeat + River sand (1:1:1) & 3.80 & 4.60 & 5.13 & $\mathbf{4 . 5 1}$ \\
\hline Vermicompost + Cocopeat (1:1) & 3.87 & 4.20 & 4.60 & $\mathbf{4 . 2 2}$ \\
\hline Vermicompost + River sand (1:1) & 3.80 & 5.00 & 5.20 & $\mathbf{4 . 6 7}$ \\
\hline Cocopeat + River sand (1:1) & 5.07 & 5.40 & 5.80 & $\mathbf{5 . 4 2}$ \\
\hline Cocopeat + Vermiculite + Perlite (3:1:1) & 4.00 & 5.20 & 5.20 & $\mathbf{4 . 8 0}$ \\
\hline Mean & $\mathbf{3 . 9 4}$ & $\mathbf{4 . 6 0}$ & $\mathbf{4 . 9 1}$ & \\
\hline C.D. at 5\% & Media & Concentration & \multicolumn{2}{|c|}{ Media X } \\
& & of IBA & Concentration \\
& & & of IBA \\
\hline
\end{tabular}


Table.5 Effect of different rooting media and IBA concentrations on diameter of flower $(\mathrm{cm})$ at full bloom stage in carnation cv. Gaudina

\begin{tabular}{|c|c|c|c|c|}
\hline \multirow{2}{*}{ Rooting media } & \multicolumn{3}{|c|}{ Concentration of IBA $(\mathbf{p p m})$} & \multirow{2}{*}{ Mean } \\
\cline { 2 - 4 } & $\mathbf{0}$ & $\mathbf{1 0 0}$ & $\mathbf{2 0 0}$ & \\
\hline River sand (Control) & 2.55 & 2.95 & 4.71 & $\mathbf{3 . 4 0}$ \\
\hline Cocopeat & 3.77 & 4.26 & 4.47 & $\mathbf{4 . 1 7}$ \\
\hline Vermicompost + Cocopeat + River sand (1:1:1) & 3.67 & 4.30 & 5.25 & $\mathbf{4 . 4 1}$ \\
\hline Vermicompost + Cocopeat (1:1) & 4.74 & 5.14 & 5.22 & $\mathbf{5 . 0 3}$ \\
\hline Vermicompost + River sand (1:1) & 4.47 & 4.66 & 5.34 & $\mathbf{4 . 8 2}$ \\
\hline Cocopeat + River sand (1:1) & 4.80 & 5.06 & 5.61 & $\mathbf{5 . 1 6}$ \\
\hline Cocopeat + Vermiculite + Perlite (3:1:1) & 4.01 & 4.90 & 5.39 & $\mathbf{4 . 7 7}$ \\
\hline Mean & $\mathbf{4 . 0 0}$ & $\mathbf{4 . 4 7}$ & $\mathbf{5 . 1 4}$ & \\
\hline C.D. at 5\% & Media & Concentration & Media x \\
& & of IBA & Concentration \\
& & & of IBA \\
\hline
\end{tabular}

Table.6 Effect of different rooting media and IBA concentrations on stalk length $(\mathrm{cm})$ in carnation cv. Gaudina

\begin{tabular}{|c|c|c|c|c|}
\hline \multirow{2}{*}{ Rooting media } & \multicolumn{3}{|c|}{ Concentration of IBA (ppm) } & \multirow{2}{*}{ Mean } \\
\cline { 2 - 4 } & $\mathbf{0}$ & $\mathbf{1 0 0}$ & $\mathbf{2 0 0}$ & \\
\hline River sand (Control) & 33.80 & 36.87 & 41.00 & $\mathbf{3 7 . 2 2}$ \\
\hline Cocopeat & 41.33 & 52.83 & 53.17 & $\mathbf{4 9 . 1 1}$ \\
\hline Vermicompost + Cocopeat + River sand (1:1:1) & 44.00 & 44.58 & 54.49 & $\mathbf{4 7 . 6 9}$ \\
\hline Vermicompost + Cocopeat (1:1) & 45.95 & 48.75 & 55.09 & $\mathbf{4 9 . 9 3}$ \\
\hline Vermicompost + River sand (1:1) & 46.74 & 50.51 & 53.18 & $\mathbf{5 0 . 1 4}$ \\
\hline Cocopeat + River sand (1:1) & 49.53 & 52.60 & 58.12 & $\mathbf{5 3 . 4 2}$ \\
\hline Cocopeat + Vermiculite + Perlite (3:1:1) & 37.79 & 46.97 & 50.15 & $\mathbf{4 4 . 9 7}$ \\
\hline Mean & $\mathbf{4 2 . 7 4}$ & $\mathbf{4 7 . 5 9}$ & $\mathbf{5 2 . 1 7}$ & \\
\hline C.D. at 5\% & Media & Concentration & Media X \\
& & of IBA & Concentration of \\
& & & IBA \\
\hline & $\mathbf{2 . 0 0}$ & $\mathbf{1 . 3 1}$ & $\mathbf{3 . 4 7}$ \\
\hline
\end{tabular}


These finding are in agreement with those of Duttet al., (2002) investigated that coco peat + compost showed maximum number of flowers in chrysanthemum. This finding also gets support from the work of Khalaj et al., (2011) in Gerbera.

\section{Diameter of flower $(\mathrm{cm})$}

The data recorded on diameter of flower are presented in Table 13. The data reveals that diameter of flower significantly differs with the different rooting media and IBA concentration.

Among the media, the maximum diameter of flower $(5.16 \mathrm{~cm})$ was recorded with the cocopeat + river sand $(1: 1)$ followed by 5.03 $\mathrm{cm}$ with vermicompost + cocopeat (1:1). Cuttings treated with 200 ppm IBA recorded the maximum diameter of flower $(5.14 \mathrm{~cm})$. The best combination for diameter of flower was found with cocopeat + river sand (1:1) rooting media with $200 \mathrm{ppm}$ IBA $(5.61 \mathrm{~cm})$.

Better root system and luxuriant growth with more number of leaves per plant had more availability of primary and secondary metabolites thus higher source to sink ratio which ultimately resulted in the increase in diameter of flower. This finding also gets support from the experimentation of Baghele et al., (2012) on rose, Chauahan et al., (2014), Sainath et al., (2014) in chrysanthemum, Pooja et al., (2015) in gladiolus, Sajid et al., (2016) in Chrysanthemum.

\section{Stalk length (cm)}

Stalk length of flower significantly differs with the different rooting media and IBA concentration. Among the rooting media used, maximum stalk length $(53.42 \mathrm{~cm})$ was observed with cocopeat + river sand (1:1) rooting media.
Treatment of cuttings with 200 ppm IBA recorded the maximum stalk length (52.17 $\mathrm{cm})$. The best combination regarding the maximum stalk length was observed with cocopeat + river sand (1:1) rooting media with $200 \mathrm{ppm}$ IBA $(58.12 \mathrm{~cm})$. The increase in stalk length might be due to effective cell division and internode's elongation because of better root growth, better uptake of water and available nutrients. The present findings also get support from the reports of Le QuocDien (2003), who reported that the maximum stalk length was observed in cocopeat medium which was at par with cocopeat + sawdust + sand $(1: 1: 1)$, cocopeat + sawdust + soil $(1: 1: 1)$ and sawdust alone. These findings were in close proximity with the findings of Chakradhar and Khirathkar (2003) in Rose, Kumar et al., (2012) in Carnation and Baghele et al., (2012) in Rose.

Based on the findings of the experiment, it is concluded from above results that among the different rooting media studied, the media comprised of cocopeat + river sand (1:1) and among the different concentrations of IBA, 200 ppm IBA was recorded best for days to initiation of first flower bud, days to 50 percent flowering, number of floral buds per plant, number of flowers per plant, diameter of flower and stalk length of flower. Within the interaction treatments, the best combination for all these parameters was found with the cocopeat + river sand $(1: 1)$ rooting media and 200 ppm IBA concentration except for the number of days to 50 percent flowering where interaction was found non- significant.

\section{Acknowledgement}

With sincerity and immense pleasure, I feel great pride and privilege to express profound sense of gratitude and heartiest indebtedness to my guide Dr. Arvind Malik, Assistant Professor, Department of Horticulture, Chaudhary Charan Singh Haryana 
Agricultural University, Hisar and my advisory committee for their untiring guidance, positive suggestion and selfdedication enable me to complete this study, without which the very existence of this research work would have been impossible.

\section{References}

Anuje, A.A., Dalal, S.R., Gonge, U.S. and Deshpande, R.M. 2004.Effect of growing media on growth, flowering and yield of Gerbera under polyhouse conditions. Orissa J. Hortic. 32(2): 106-108.

Baghele, R. D., B. K. Dhaduk, S. L. Chawla and Radhika J. 2012. Effect of foliar spray of growth regulator and cow urine on flowering, quality and yield of rose (Rosa hybrid cv. poison) under naturally ventilated polyhouse. Intl. J. Tropical Agric.34(6): 0254-8755.

Baheer, R. 1997.Yield and post-harvest quality of 12 gerbera cultivars grown in two coco peat based substrates on a hydroponic culture system. Chania: 94.

Barreto, M.S. and Jagtap, K.B. 2002. Studies on polyhouse Gerbera substrate. In: Flori. Res. Trend in India, ISOH, New Delhi: 173-176.

Benny, J.C., Devi, S., Fatmi, U. and Jose, D.A. 2017. Effect of plant growth regulators, Gibberellic acid $\left(\mathrm{GA}_{3}\right)$ and Naphthalene Acetic Acid (NAA) on growth and yield of carnation (Dianthus caryophyllus L.) under naturally ventilated polyhouse. Plant Archives. 17(2): 803-812.

Chakradhar, M. and KhirathkarS. D. 2003. Growth and flowering response of rose Cv. Gladiator to certain growth regulators sprays. South Indian Hort., 51(1-6): 46-50.

Chauhan, R.V.,Varu, D.K., Kava, K.P. and Savaliya, V. M. 2014. Effect of different media on growth, flowering and cut flower yield of gerbera under protected condition. The Asian J. Hortic., 9(1):228-231.

Dole, J.M. and Wilkins, H.F. (2005). Floriculture: principles and species, 2nd edition. Pearson Prentice Hall, Upper Saddle River, New Jersey: 347.

Dutt, M., Patil, M.T. and Sonawane, P.C. 2002. Effect of various substrates on growth and flowering of chrysanthemum. Indian J. Hortic., 59(2): 191-195.

El- Naggar, A. H. (2009). Response of Dianthus caryophyllus L. plants to foliar nutrition. World J. Agric. Sci.,5(5): 622- 630.

Jawahar, L.M., Joshua, M.J.P., Subramanium, A.S. and Kumar, M.V. (2001). Standardization of growing media for anthurium (Anthurium andreanum) cv. 'Temptation' under shade net house. South Indian Hort., 49(2): 323-328.

Kaviarasu, A. and N. Selvaraj (2016). Effect of growth regulators on standard carnation (Dianthus caryophyllus L.) cuttings under polyhouse condition in different var. Domingo, Baltico and Bizet. Advances in Life Sci., 5(4): 1510-1513.

Khalaj, M. A., Amiri, M. and Sindhu, S.S. 2011. Study on the effect of different growing media on the growth and yield of gerbera (Gerbera jamesonii L.). J. Ornam. Hortic. Plants, 1(3): 185-189.

Kumar, V., Kumar, V., Umrao, V. and Singh, M. 2012. Effect of $\mathrm{GA}_{3}$ and IAA on growth and flowering of carnation. Hortflora Research Spectrum.

Le, Q.D. (2003). Standardization of growing media under protected environment in Gerbera (Gerbera jamesonii). M.Sc. thesis submitted to Dr. Yashwant Singh Parmar University of Horticulture and Forestry, Nauni, Solan (H.P), India. 
Maitra, S. and N. Roychowdhury 2015. Effect of plant growth regulators on growth, development and flowering of carnation (Dianthus caryophyllus L.) cv. Chabaud Super Mix. J. Agric. Technol., 2(1\&2):72-78.

Panse, V. G. and Sukhatme, P. V. 1985. Statistical Methods for Agricultural Workers. New Delhi ICAR Publication (2nd Ed.).

Pooja, R., Y. Kuldeep, K. Nisha, S. Narender, H. D. Muzafar and G. Rameshwar (2015). Assessment of growth, floral and yield attributes of gladiolus in response to Gibberellic Acid treatment. Botany Res. Intl.,8(1): 01-06.

Prince, Mailk, A., and Beniwal, V. (2017). Influence of indole-3-butyric acid on rooting efficacy in different carnation (Dianthus caryophyllus L.) genotypes under protected condition. Chem. Sci. Rev. Lett.,6(23): 1858-1862.

Rani, P. and P. Singh (2013). Impact of Gibberellic acid pretreatment on growth and flowering of tuberose (Polianthes tuberosa L.) cv. Prajwal. J. Trop. Plant Physiol., 5: 33-41.

SainathUppar, D. S., V. S. Patil, V. K. Deshpande and Ravi Hunje (2014).
Effect of different growth regulators on seed yield and quality attributes in annual chrysanthemum (Chrysanthemum coronarium L.). Karnataka J. Agric. Sci.,27(2): 131134

Sajid, M. A., Noorul, A. Habib and K. Khalid (2016). Effect of Gibberellic acid on enhancing flowering time In Chrysanthemum morifolium. Pak. J. Bot.,48(2): 477- 483.

Sanyat, P.S. and Mishra, R.L. (2006). Carnation. In: advances in ornamental horticulture. S.K. Bhattacharjee (Ed.), Vol.2, Pointer Publishers, Jaipur, India: 66-80.

Sekar, K. and Sujata, A. (2001). Effect of growing media and $\mathrm{GA}_{3}$ on growth and flowering of Gerbera (Gerbera jamesonii $\mathrm{H}$. Bolus) under naturally ventilated greenhouse. South Indian Hortic, 49: 338-339.

Talukdar, M., Paswan, L. and Barua, S. (1991). Flowering behaviour in relation to different pot mixture treatments in orchids. J. Orchid Soc. India,5(1, 2): 55-59.

\section{How to cite this article:}

Sushil Kumar, Arvind Malik and Ritu Yadav. 2019. Effect of the different Rooting Media and IBA Concentrations on Yield of Carnation (Dianthus caryophyllus) Cuttings cv. Gaudina. Int.J.Curr.Microbiol.App.Sci. 8(10): 335-343. doi: https://doi.org/10.20546/ijcmas.2019.810.034 